\title{
Cianobactérias de água doce e saúde pública: uma revisão
}

\author{
Danilo Barbosa Siqueira ${ }^{1}$ \\ Eduardo Cyrino Oliveira-Filho ${ }^{2}$
}

\begin{abstract}
RESUMO - A descarga de matéria orgânica oriunda de atividades humanas em ambientes aquáticos comprome o desenvolvimento nos centros urbanos. A acumulação de nutrientes nos corpos hídricos induz ao fenômeno conhecido como eutrofização. Nessas condições, as florações de cianobactérias tornam-se comuns causando impacto social, econômico e ambiental. Além do odor e sabor desagradável, a decomposição destas florações libera metabólitos altamente tóxicos para seres humanos, animais e comunidades aquáticas, gerando sérias consequiências. Baseado em revisão da literatura, o presente artigo expõe o problema e apresenta tópicos relacionados à prevenção, ao controle e à regulamentação.
\end{abstract}

Palavras - chave: cianobactérias, eutrofização, cianotoxinas, poluição, toxicologia.

\section{Freshwater cyanobacteria and public health: an overview}

\begin{abstract}
The input of organic material, mainly proceeding of anthropogenic activities, in aquatic environments, has been committing the development of the urban centers. The disposal of nutrients into watercourses induces a phenomenon called eutrophication. These conditions stimulate the appearance of cyanobacterial blooms that causes social, economic and environmental impacts. Besides the odor and unpleasant flavor, the decomposition of these blooms releases metabolites toxic to human beings, animals and aquatic communities. Based on a bibliographic review, the present paper introduces the subject and makes an approach on topics related to prevention, control and regulations.
\end{abstract}

Key words: cyanobacteria, eutrofization, cianotoxins, pollution, toxicology.

Monografia apresentada para conclusão do curso de Biomedicina no UniCEUB.

${ }^{1}$ Biomédico (UniCEUB).

${ }^{2}$ Professor de Toxicologia na FACS/UniCEUB e pesquisador na Embrapa Cerrados.

E-mail: cyrino@cpac.embrapa.br 
A contaminação ambiental e a degradação da qualidade das águas tornaram-se preocupações da sociedade, além de serem tema de eventos científicos nos últimos anos. A eutrofização é um dos principais fatores responsáveis pela redução da qualidade das águas naturais; trata-se de fenômeno de grande repercussão e debate pelo fato de ser gerado, em grande parte, por resíduos oriundos de atividades humanas.

A degradação do meio ambiente acontece por negligência ou por desconhecimento de medidas de controle. Como conseqüência disso, ocorrem o enriquecimento das águas com nutrientes e o aumento da produtividade da comunidade fitoplanctônica, com dominância das cianobactérias ou algas cianofíceas. As florações de cianobactérias causam impactos sociais, econômicos e ambientais, principalmente pela produção de metabólitos secundários bioativos com altas propriedades tóxicas que podem afetar a saúde de muitos animais, inclusive do homem ${ }^{1}$.

Aumento crescente no número de registros de danos causados à saúde e ao ambiente em decorrência do desenvolvimento de populações de cianobactérias tem sido relatado, entre eles, casos graves de intoxicação humana ocorridos em vários países, inclusive no Brasil ${ }^{2}$. Nesse contexto, este estudo tem como objetivo apresentar o impacto das florações tóxicas de cianobactérias sobre a saúde humana e o ambiente, apresentando tópicos relacionados à prevenção, ao controle e à regulamentação.

\section{Cianobactérias}

As algas azuis, cianofíceas ou cianobactérias, são microorganismos que não podem ser considerados algas, tampouco bactérias comuns. Possuem características celulares de procariontes (ausência de membrana nuclear) e sistema fotossintetizante semelhante ao das algas (apresenta fotossistemas um e dois, porém não organizados em cloroplastos). Houve confusão na nomenclatura destes seres, pois, a princípio, pensou tratar-se de algas unicelulares, posteriormente, os estudos demonstraram que possuem características de bactérias, compreendidas, portanto, no reino Monera .

Possuem tipos de pigmentos acessórios, incluindo carotenóides, que podem ser encontrados nos eucariontes fotossintetizantes e em algumas bactérias. Também podem conter dois tipos de ficobilinas: ficocianina, pigmento azul que está sempre presente, e ficoeritrina, de cor vermelha, nem sempre presente. Os

\footnotetext{
1 YUNES, 1998.

${ }^{2}$ CARMICHAEL et al, 2001.

${ }^{3}$ TRABULSI, 1999.
} 
pigmentos não estão armazenados em plastídios, mas espalhados em um sistema de membranas na porção periférica da célula. Sua parede celular é destituída de celulose, porém é constituída do mesmo tipo de polissacarídeo encadeado com polipeptídeos que forma a parede das bactérias ${ }^{4}$. Contém lipopolissacarídeos, podendo ser classificada como gram-negativa.

Suas células não possuem cílios, flagelos ou qualquer outro tipo de estrutura para locomoção. Entretanto, algumas formas filamentosas podem mover-se em um deslizamento combinado com uma rotação da célula, em torno de seu eixo longitudinal. As cianobactérias também possuem movimentos espasmódicos intermitentes. Podem apresentar-se na forma unicelular, ou filamentosa. Algumas formam filamentos ramificados, e outras formam placas ou colônias irregulares. Como acontece em bactérias pluricelulares, as células estão interligadas somente por suas paredes externas ou bainhas gelatinosas, sendo cada célula independente da outra ${ }^{5}$. A reprodução acontece por divisão celular. Qualquer célula de uma colônia de cianobactérias pode dividir-se, e suas subunidades, quando afastadas, formam novas colônias. Em algumas situações, a transformação foi observada experimentalmente. As formas coloniais e filamentosas apresentam vários tipos de fragmentação em seu talo. Fragmentos pluricelulares denominam-se hormogônias. Gêneros de origem filamentosa, como Nostoc e Anabaena, possuem a capacidade de gerar heterocistos, células ampliadas com uma parede multiestratificada, onde os tilacóides se reagrupam em padrão concêntrico ou reticulado. Em determinadas situações, as células vegetativas desses gêneros podem transformar-se em esporos de paredes grossas, chamados de acinetos ${ }^{6}$.

As cianobactérias associam-se em simbiose com outros seres vivos, tais como: amebas, diatomáceas, protozoários flagelados, certas algas verdes sem clorofila, outras algas azuis, plantas superiores e fungos cenocíticos. Em simbiose, não há presença de parede celular. Portanto, funcionalmente, as cianobactérias comportam-se como cloroplastos, pois dividem-se ao mesmo tempo em que a célula hospedeira ${ }^{7}$. É freqüente aparecerem como membros assimiladores nos liquens e associadas a briófitas e plantas vasculares, desempenhando a função de fixar nitrogênio. Várias espécies de cianobactérias possuem a capacidade de fixar nitrogênio. Em virtude desse potencial, podem colonizar áreas nuas sobre rochas e solo. A formação de heterocistos em Nostoc e em outros gêneros é inibida pela presença de amônia e nitratos. Porém, quando tais compostos caem abaixo de certo limiar, os heterocistos começam a surgir ${ }^{8}$.

\footnotetext{
${ }^{4}$ BRYANT, 1994.

${ }^{5}$ OLIVEIRA, 1996.

${ }^{6}$ BRYANT, 1994.

${ }^{7}$ OLIVEIRA, 1996.

${ }^{8}$ ESTEVES, 1998.
} 


\section{Eutrofização}

Eutrofização é o fenômeno caracterizado como aumento da concentração de nutrientes, especialmente fósforo e nitrogênio, nos ecossistemas aquáticos, que gera o aumento da produtividade do corpo hídrico. Em decorrência deste processo, o ecossistema passa da condição de oligotrófico e mesotrófico para eutrófico ou hipereutrófico.

A eutrofização pode ser observada em virtude de processos naturais e artificiais. Quando natural, é lenta e contínua e resulta do aporte de nutrientes trazidos pelas chuvas e pelas águas superficiais que lavam a superfície terrestre ${ }^{9}$. O processo é dinâmico e leva a modificações qualitativas e quantitativas na comunidade aquática, nas características químicas e físicas do meio e, principalmente no nível de produção ${ }^{10}$. Quando ocorre artificialmente, por atividades humanas, os nutrientes são originários de atividades domésticas, urbanas e agrícolas.

$\mathrm{O}$ aumento da industrialização, do crescimento populacional, os fatores socioculturais, o uso de fertilizantes químicos na agricultura e de produtos saneantes domissanitários contendo compostos polifosfatados têm sido a maior causa de eutrofia em ecossistemas aquáticos. A liberação de fósforo e nitrogênio no meio está relacionada com o desencadeamento do processo de eutrofização, devido à ação destes elementos como fatores limitantes na produção primária de ecossistemas, pois estes estão relacionados com o processo de fotossíntese ${ }^{11}$. Segundo Von Sperling (1996) o processo de eutrofização de corpos hídricos pode também estar relacionado com a forma de uso do solo e de ocupação da bacia hidrográfica.

Várias podem ser as formas de liberação artificial de nutrientes, principalmente nitrogênio e fósforo, para o interior dos ambientes hídricos. Dentre estas, destacam-se os efluentes agrícolas, domésticos, industriais e gerados pela chu$\mathrm{va}^{12}$.

\section{Efluentes oriundos da agricultura}

A retirada da vegetação natural de uma bacia para ocupação por agricultura, geralmente, representa etapa intermediária no processo de eutrofização de um corpo hídrico. As culturas plantadas na bacia são retiradas para consumo humano. A retirada de nutrientes, não compensada naturalmente, causa quebra em seu

\footnotetext{
${ }^{9}$ ESTEVES, 1998.

${ }^{10}$ FERNANDES, 1993.

${ }^{11}$ ESTEVES, 1998.

${ }^{12}$ WAKIDA \& LERNER, 2005.
} 
ciclo interno. Para compensar a perda e aumentar a produtividade do solo, fertilizantes químicos com grandes concentrações de fósforo e nitrogênio são utilizados em grandes quantidades, superiores à capacidade de absorção dos vegetais ${ }^{13}$.

A ocupação da vegetação natural pela agricultura pode causar redução na capacidade de infiltração do solo. Assim, os nutrientes geralmente adicionados em excesso, tendem a escoar-se superficialmente pelo terreno até atingir os corpos d'água. Em consequiência, há aumento no número de algas e de organismos consumidores ${ }^{14}$.

\section{Efluentes domésticos}

Com a utilização de detergentes sintéticos, o fenômeno da eutrofização passou a ser mais freqüente. Estes compostos têm a função principal de solubilizar gorduras e impurezas. Em sua composição, algumas substâncias, como polifosfatos, carbonatos e silicatos, auxiliam o processo de limpeza ${ }^{15}$.

No que diz respeito aos dejetos humanos, além dos problemas sanitários diretos, tais como, perda de balneabilidade, odores indesejáveis, inviabilização da distribuição de água, proliferação de insetos causadores de doenças, também podem gerar, a médio e longo prazo, a eutrofização de corpos d'água pelas consideráveis concentrações de nitrogênio e fósforo e pela composição orgânica dos esgotos, ricos em nutrientes. Poucas pesquisas apresentam esse assunto com enfoque quantitativo. Uma delas, realizada por Netto e Dutra Filho em 1981 apud Esteves (1998), no lago Paranoá (Brasília, DF), demonstrou que os efluentes das duas estações de tratamento de esgotos lançados são as principais fontes de fosfato antrópico e, conseqüentemente, as maiores responsáveis pela eutrofização natural. Os efluentes despejados no lago em 1980 pelas estações de tratamento contribuíram com $70 \%$ da quantidade total de fosfato daquele ano, correspondendo a 82 toneladas.

\section{Efluentes oriundos de indústrias}

Compostos à base de nitrogênio são utilizados em processos industriais. Alguns exemplos de uso são para tratamentos de plásticos e metais nas matériasprimas da indústria têxtil, na fabricação de compensados, na indústria de produtos de limpeza e de medicamentos. A contaminação, em geral, é resultado de ma-

\footnotetext{
${ }^{13}$ OLIVEIRA-FILHO \& LIMA, 2002.

${ }^{14}$ VON SPERLING, 1996.

${ }^{15}$ VON SPERLING, 1996.
} 
nuseio, descarga e uso inadequados. Os compostos predominantes são amônia, ácido nítrico, uréia e nitrato de amônio. Assim, é possível encontrar tais fontes de nitrogênio em efluentes, ocasionando impactos significativos na qualidade da água em regiões industriais ${ }^{16}$.

\section{Efluentes oriundos de chuvas}

Em regiões de intensa poluição atmosférica, as chuvas constituem significativa fonte de fósforo e nitrogênio. $\mathrm{O}$ aporte de nutrientes varia de região para região e é influenciado pelas condições meteorológicas. Lagos localizados próximos a rodovias tendem a receber aporte adicional de fosfato e nitrogênio em decorrência do tráfego de veículos, principalmente no período de chuvas ${ }^{17}$.

Conforme comentado, várias podem ser as consequiências do processo de eutrofização. Entre elas, citam-se problemas estéticos e recreacionais, condições anaeróbias no sedimento dos corpos d'água, mortandade de organismos aquáticos, maior dificuldade e elevação dos custos para tratamento da água, toxicidade das algas presentes, alteração na qualidade e na quantidade de organismos aquáticos, redução da capacidade de navegação e transporte e, por fim, o desaparecimento gradual do corpo d'água via assoreamento ${ }^{18}$.

A diminuição dos níveis de $\mathrm{O}_{2}$ geralmente, acontece após longos períodos de insolação (muita energia luminosa para fotossíntese). Dessa forma, as algas podem atingir superpopulações, criando espécie de malha ou película superficial sobre o corpo d'água, impedindo, assim, a entrada de raios solares nas camadas mais profundas, causando a morte de algas situadas nestas regiões. $\mathrm{O}$ aumento na produção do corpo d'água como um todo leva à maior concentração de organismos, entre esses, bactérias heterotróficas, que se alimentam da matéria orgânica das algas e outros microorganismos mortos, aumentando o consumo do oxigênio dissolvido no meio. Em decorrência da sedimentação da matéria orgânica, da reduzida entrada de oxigênio a estas profundidades e da ausência de fotossíntese (pela baixa penetração dos raios solares), o fundo do corpo d'água apresenta comportamento anaeróbico ${ }^{19}$.

Em períodos de mistura total de massa líquida (quando há inversão térmica) e em ausência de fotossíntese (no período noturno), se a concentração de bactérias anaeróbias estiver alta, pode haver a morte de organismos aquáticos e a reintrodução de compostos antes reduzidos na massa líquida, ocorrendo, assim,

\footnotetext{
${ }^{16}$ WAKIDA \& LERNER, 2005.

${ }^{17}$ ESTEVES, 1998.

${ }^{18}$ VON SPERLING, 1996.

${ }^{19}$ FERNANDES, 2003.
} 
diminuição da qualidade da água em suas propriedades químicas e físicas ${ }^{20}$.

A baixa qualidade da água leva a maiores custos no tratamento, pois faz-se necessária a remoção das algas, da coloração da água, do sabor e do odor, gerando maior utilização de produtos químicos. Isso pode também ser caracterizado como problema econômico e comercial causado pela eutrofização ${ }^{21}$. Além disso, o abastecimento de água para indústrias também pode ser prejudicado pelo mesmo motivo. $\mathrm{O}$ assoreamento e a eutrofização podem, em longo prazo, provocar o desaparecimento do corpo d'água. Normalmente, trata-se de processo lento e irreversível que pode ser acelerado pela presença do homem ${ }^{22}$.

\section{Toxinas das cianobactérias}

As cianobactérias de água doce possuem a capacidade de produzir toxinas em larga escala, liberadas como metabólitos secundários. Todas as cianobactérias oriundas de um bloom ou de um scum possuem a capacidade de produzir toxinas. Em estudos sistemáticos, cerca de $25 \%$ a $70 \%$ das florações de cianobactérias mostraram ser potencialmente tóxicas. Dos cerca de 50 gêneros de cianobactérias de água doce, no mínimo, sete (Anabaena, Aphanizomenon, Coelosphaerium, Gloetrichia, Microcystis, Nodularia e Nostoc) contêm espécies tóxicas ${ }^{23}$.

Os fatores que favorecem a produção das toxinas são variáveis e pouco entendidos. Há evidências de que a produção e a acumulação estão relacionadas com o crescimento das colônias. De fato, nos períodos de crescimento exponencial, a produção de toxinas tende a aumentar enquanto, na fase estacionária de crescimento, a produção tende a cair ${ }^{24}$. Em alguns casos, a concentração de toxinas tem sido relacionada com fatores, tais como, produção primária de clorofila-a, radiação solar, temperatura superficial da água, $\mathrm{pH}$, e porcentagem de saturação de oxigênio.

A temperatura é fator importante na produção de toxinas. Em M. aeruginosa, a produção de toxinas teve aumento e diminuição proporcionais a aumento e redução da temperatura ótima ${ }^{25}$. A temperatura ótima varia de espécie para espécie, de acordo com seu metabolismo, o que pode ocasionar o declínio da colônia e, por conseguinte, a diminuição na produção de toxinas ${ }^{26}$.

\footnotetext{
${ }^{20}$ CHORUS \& BARTRAM, 1999.

${ }^{21}$ CAMPOS, 1999.

22 ESTEVES, 1998.

${ }^{23}$ DUY et al, 2000.

${ }^{24}$ WATANABE \& OISHI, 1985.

${ }^{25}$ RESSOM et al., 1994.

${ }^{26}$ DUY et al., 2000.
} 
A oferta de nutrientes possui papel fundamental tanto no crescimento quanto na produção de cianotoxinas. Foi observada redução de até dez vezes na toxicidade de Microcystis sp. após a retirada do nitrogênio e do carbono inorgânico da cultura. Os gêneros não-fixadores de nitrogênio, como Microcystis e Oscillatoria, produzem mais toxinas quando há nitrogênio abundante. Por outro lado, os gêneros fixadores não são dependentes de nitrogênio no meio para sua produção de toxinas. A diferença induzida por alta ou baixa concentração de fósforo variou entre duas e quatro vezes. Em estudos de campo, foi encontrada relação entre fósforo total e a concentração de microcistina-LR em células de Microcystis aeruginosa ou em material coletado num bloom de Microcystis sp. Em estudos relativos à presença de metais traço, apenas o zinco parece ter real importância, enquanto estudos acerca do ferro mostraram-se contraditórios ${ }^{27}$. O zinco é necessário para o crescimento ótimo das colônias, assim como para a produção de toxinas em M. aeruginosa, em crescimento em grupo $^{28}$.

Pouca informação confiável ou disponível foi encontrada a respeito dos efeitos de processos metabólicos ou genéticos que regulam a produção de toxinas. Como ela varia entre cepas da mesma espécie, acredita-se que seja regulada em nível molecular. Os primeiros estudos investigaram o possível envolvimento de plasmídeos no processo. Foi especulado que continham os genes responsáveis pela regulação na produção de toxinas (DUY et al, 2000). Todavia, quatro cepas tóxicas de $M$. aeruginosa continham os plasmídeos, enquanto, em três outras cepas não-tóxicas e outra tóxica, o plasmídeo não foi encontrado ${ }^{29}$.

No entanto, multi-complexos de enzimas e genes de síntese de peptídeos estão envolvidos na produção de hepatotoxinas. Peptídeos cíclicos e lineares, freqüentemente com D-aminoácidos, são conhecidos por serem produzidos, não pela via ribossomal, mas por multi-sítios de síntese de peptídeos, parcialmente seqüenciados em Microcystis aeruginosa ${ }^{30}$. Em importante experimento, Dittman et al. (1997) demonstraram que os genes responsáveis pela síntese de peptídeos o são também pela produção da microcistina.

As cianotoxinas apresentam características diversas tanto do ponto de vista químico como do toxicológico. Os mecanismos toxicológicos descritos e conhecidos são diferenviados, e os efeitos podem variar de hepatotóxicos, neurotóxicos até a completa inibição da síntese de proteínas. Para melhor entender tais efeitos, é necessário entender quais são as propriedades químicas e físicas das cianotoxinas $^{31}$.

\footnotetext{
${ }^{27}$ CHORUS \& BARTRAM, 1999.

${ }^{28}$ DUY et al, 2000.

${ }^{29}$ CHORUS \& BARTRAM, 1999.

${ }^{30}$ MEISSNER et al, 1996.

${ }^{31}$ CHORUS \& BARTRAM, 1999.
} 


\section{Classificação das cianotoxinas}

As cianotoxinas podem ser classificadas em três grupos, de acordo com a estrutura química: peptídeos cíclicos, alcalóides e lipopolissacarídeos. O primeiro grupo é definido pela presença de toxinas hepatotóxicas, como a microcistina e a nodularina, freqüentemente encontradas tanto em água doce como salgada. Elas representam desafio ao tratamento de água potável onde há a presença de cianobactérias produtoras dessas toxinas. Em bioensaios com ratos, as hepatotoxinas causam morte por hemorragia no fígado em poucas horas ${ }^{32}$.

Em comparação com outros oligopeptídeos e polipeptídeos celulares, como as proteínas com alto peso molecular (MW > 10.000), os peptídeos cíclicos (MW $=800-1.100$ ) possuem tamanho relativamente pequeno. Eles possuem sete (para microcistina) ou (para nodularina) aminoácidos, com os dois últimos condensados para formar um composto cíclico. Estes peptídeos cíclicos são hidrosolúveis, incapazes de penetrar diretamente as membranas lípidicas de animais, plantas ou bactérias, com exceção de algumas microcistinas hidrofóbicas. Para realizarem seu efeito tóxico, a entrada nas células ocorre através de transportadores de membrana, que carreiam íons e nutrientes. Em ambientes aquáticos, essas toxinas permanecem no interior das cianobactérias e só são liberadas em lise celular. Pelas suas características, tais como, alta estabilidade química e hidrossolubilidade, representam grande risco de contaminação do meio ambiente e possível contaminação de seres humanos. As toxinas com estrutura de alcalóides formam grupo bem diverso tanto em estrutura química como em toxicidade para mamíferos. Os alcalóides fazem parte de grande grupo de componentes heterocíclicos nitrogenados, geralmente, com pouco peso molecular $(\mathrm{MW}<1,000)$. São produzidos por plantas e algumas bactérias, comumente tóxicos e invariavelmente bioativos. As nãosulfatadas toxinas alcalóides de cianobactérias de água doce (anatoxina-a e saxitoxina) são todas neurotóxicas, mas as sulfatadas PSP's, c-toxinas e as goniautoxinas (derivados sulfatados da saxitoxina) também são neurotoxinas ${ }^{33}$.

A maior ocorrência dessas neurotoxinas está nos Estados Unidos, na Europa e na Austrália. Em bioensaios com ratos, a morte ocorre por rápida parada respiratória (de 2 a 30 minutos). Os conhecidos representantes das neurotoxinas são: anatoxina-a e homoanatoxina-a, que mimetizam o efeito da acetilcolina; anatoxinaa (S), que é um anti-colinesterásico; as saxitoxinas, mais comumente conhecidas como PSP's (paralytic shellfish poisons) e as neosaxitoxinas, ambas com capacidade de bloquear os canais de sódio das células nervosas ${ }^{34}$.

${ }^{32}$ CHORUS \& BARTRAM, 1999.

${ }^{33}$ CHORUS \& BARTRAM, 1999.

${ }^{34}$ DUY et al, 2000. 
As toxinas citotóxicas podem ser melhor representadas pela cilindrospermopsina, que é um alcalóide cíclico de guanidina, com peso molecular de 415, produzido pelas espécies Cylindrospermopsis raciborskii, Umezakia natans e por Aphanizomenon ovalisporum. Em sua forma pura, é hepatotóxica. Contudo, extratos crus de cepas de $C$. raciborskii, diretamente injetadas ou introduzidas oralmente em ratos, também causaram patologias em rins, baço, timo e coração. $\mathrm{Na}$ forma pura, apresenta $\mathrm{DL}_{50}$ para ratos, igual a 2,1 mg/kg (i.p.), em 24 horas, e 0,2 $\mathrm{mg} / \mathrm{kg}$, em cinco ou seis dias. Sua maior ocorrência está na Austrália, onde, recentemente, foi descoberto novo tipo de cilindrospermopsina, a demetoxicilindrospermopsina ${ }^{35}$. Os lipopolissacarídeos, geralmente, são encontrados na membrana externa da parede celular de bactérias gram-negativas, incluindo as cianobactérias, onde formam complexos com proteínas e fosfolípideos. Em geral, são tóxicos ${ }^{36}$.

\section{Acumulação de cianotoxinas}

Poucos estudos conclusivos e significativos foram produzidos a respeito da acumulação de cianotoxinas nas cadeias alimentares. Os níveis de bioacumulação chamam a atenção para eminente risco à saúde humana, entretanto, isso dependerá do consumo e do grau de toxicidade da população de cianobactérias, onde foi feita a pesca ou o cultivo ${ }^{37}$. Em relação às toxinas de água doce, ocorre bioacumulação de microcistina em vertebrados, como peixes, e em invertebrados, como mexilhões e zooplâncton. Nos mexilhões, as maiores concentrações foram encontradas no hepatopâncreas e, em vertebrados, no fígado. Também foi confirmada a bioacumulação de microcistina-LR em salmões e em larvas de carangue$\mathrm{jo}^{38}$.

\section{Toxicidade das cianotoxinas}

Os efeitos tóxicos das cianotoxinas são diversificados e podem ser melhor compreendidos quando separados em efeitos sobre organismos aquáticos e sobre seres humanos.

${ }^{35}$ CHISWELL et al., 1999.

${ }^{36}$ CHORUS \& BARTRAM, 1999.

${ }^{37}$ BEATTIE et al, 1998.

${ }^{38}$ CHORUS \& BARTRAM, 1999. 


\section{Efeitos sobre organismos aquáticos}

De modo geral, as cianobactérias apresentam efeito deletério sobre o zooplâncton, mas a suscetibilidade é altamente variável entre gênero e espécies ${ }^{39}$. Bell \& Codd (1996) demonstraram que a microcistina pode afetar o microcrustáceo Daphnia pulicaria, reduzindo sua capacidade de filtração e a sobrevivência de seus filhotes. Pela exposição à saxitoxina e à neosaxitoxina, Sasner et al. (1984) observaram movimentos erráticos e paralisia da segunda antena de Daphnia magna, levando os organismos a afundar.

De Mott et al. (1991) demonstraram que quatro espécies do zooplâncton diferiram na sensibilidade às hepatotoxinas em quase duas ordens de grandeza. A toxicidade foi observada apenas em altíssimas concentrações, quantidades dificilmente encontradas no ambiente natural $\left(\mathrm{CL}_{50}\right.$ variando de 450 a $21.400 \mathrm{mg} / \mathrm{L}$ de microcistina, em 48 horas).

Provavelmente, em condições naturais, certas espécies e cepas do zooplâncton podem ser afetadas pelas cianotoxinas, enquanto outras, não. As cianotoxinas podem influenciar a estrutura do zooplâncton, especialmente quando as cianobactérias são grupos dominantes no fitoplâncton ${ }^{40}$.

Em testes com peixes, se doses com cianotoxinas forem administradas via intraperitoneal ou oral, os sintomas desenvolvidos são similares em mamíferos de laboratório. Enquanto severa necrose hepática e morte foram observadas em laboratório, a imersão de peixes jovens e adultos em águas contaminadas não demonstrou efeito ${ }^{41}$.

Em um bloom de cianobactérias no Reino Unido, após grande mortalidade de peixes, a análise histopatológica mostrou que a morte ocorreu por severos danos nas brânquias, no trato digestivo e no fígado. O dano nas brânquias, provavelmente, ocorreu em decorrência do alto $\mathrm{pH}$ induzido pela grande atividade fotossintetizante das cianobactérias, antes do colapso total do bloom, e pela crescente concentração de amônia, oriunda da decomposição das cianobactérias. No entanto, o dano nas brânquias pode ter facilitado a intoxicação pela microcistina, levando a posterior necrose do fígado ${ }^{42}$. Danos no fígado, coração, rim, brânquias, baço e na pele também foram observados em peixes ${ }^{43}$.

\footnotetext{
${ }^{39}$ CHORUS \& BARTRAM, 1999.

${ }^{40}$ CHORUS \& BARTRAM, 1999.

${ }^{41}$ CHORUS \& BARTRAM, 1999.

${ }^{42}$ CHORUS \& BARTRAM, 1999.

${ }^{43}$ DUY et al., 2000.
} 
No Brasil, um estudo com o caranguejo Chasmagnathus granulatus mostrou que seu hepatopâncreas apresentava túbulos necróticos e depósitos de melanina após a administração contínua de microcistina por uma semana. Enzimas do sistema de defesa antioxidante foram ativadas após a exposição à microcistina, de forma a manter os níveis de peroxidação dos lipídios, porém não foi possível evitar o dano histopatológico ${ }^{44}$.

\section{Efeitos sobre seres humanos}

As doenças gastrointestinais causadas pelo consumo de água contaminada, geralmente, são associadas com cólera, desinteria e outras doenças que possuem caráter sanitário e relacionam-se com a miséria humana. Desse modo, torna-se necessário que as possíveis patologias causadas por cianobactérias ou por suas toxinas sejam diagnosticadas em análise comparativa com doenças causadas por bactérias, protozoários e vírus ${ }^{45}$. A liberação de cianotoxinas de dentro da célula para o meio externo pode ocorrer naturalmente, pela redução na população de cianobactérias, como resultado de morte, ou por ação humana via adição de compostos algicidas, tais como, o sulfato de cobre nos corpos d'água, objetivando eliminar a floração de cianobactérias. No entanto, neste processo, também ocorre lise celular e liberação das cianotoxinas no meio externo. Embora o tratamento seja eficiente na redução da população, não possui eficácia para a eliminação das cianotoxinas do ambiente aquático ${ }^{46}$. Os sintomas causados pela intoxicação dependem da via de contaminação, da dose ingerida e do prévio estado de saúde, como, por exemplo, em pessoas que possuem doenças em órgãos suscetíveis à intoxicação por hepatotoxinas, tais como, hepatite, cirrose hepática, etc. O consumo de água também é um fator que merece relevância. De modo geral, em relação ao peso corpóreo, as crianças consomem mais água que os adultos e são, portanto, mais suscetíveis à intoxicação ${ }^{47}$. Os efeitos também dependem do tipo de toxina. Cada uma possui próprio mecanismo de toxicidade e efeitos diversos. Na Tabela 1, são apresentadas as observações clínicas, a toxicodinâmica e o número de variações estruturais que cada uma possui. Cada variação possui suas particularidades, mas também têm características semelhantes ${ }^{48}$.

\footnotetext{
${ }^{44}$ PINHO et al, 2003.

${ }^{45}$ CHORUS \& BARTRAM, 1999.

${ }^{46}$ MAXIMIANO et al., 2005.

${ }^{47}$ CHORUS \& BARTRAM, 1999.

${ }^{48}$ DUY et al., 2000.
} 
Tabela 1 - Cianotoxinas, efeitos em ratos, número de variações estruturais, toxicodinâmica e observações clínicas de acordo com DUY et al (2000).

\begin{tabular}{|c|c|c|c|c|}
\hline Cianotoxina & Efeito & $\begin{array}{c}\text { Variações } \\
\text { Estruturais }\end{array}$ & Toxicodinâmica & Observações clínicas \\
\hline Anatoxina - a & Neurotóxico & Uma & $\begin{array}{l}\text { Agonista nicotínico. Ação pós- } \\
\text { sináptica de despolarização e } \\
\text { bloqueio da atividade neuromuscular. }\end{array}$ & $\begin{array}{l}\text { Cambaleamento, } \\
\text { convulsões, salivação } \\
\text { viscosa, lacrimação (em } \\
\text { ratos), incontinência } \\
\text { urinária, fraqueza muscular } \\
\text { e morte por parada } \\
\text { respiratória em poucos } \\
\text { minutos. }\end{array}$ \\
\hline Anatoxina - a (s) & Neurotóxico & Uma & $\begin{array}{l}\text { Inibição irreversível da colinesterase } \\
\text { (ChE). }\end{array}$ & $\begin{array}{l}\text { Lacrimação, dispnéia, } \\
\text { mucosa oral cianótica, } \\
\text { defecação e crises } \\
\text { clônicas antes da morte, } \\
\text { que pode ocorrer por } \\
\text { parada respiratória. }\end{array}$ \\
\hline Saxitoxina & Neurotóxico & $\begin{array}{l}\text { Cerca de } \\
\text { seis }\end{array}$ & $\begin{array}{l}\text { Bloqueio dos canais de sódio. } \\
\text { Inibição da transmissão nervosa. }\end{array}$ & Não documentado. \\
\hline Neosaxitoxina & Neurotóxico & - & $\begin{array}{l}\text { Bloqueio dos canais de sódio. } \\
\text { Inibição da transmissão nervosa. }\end{array}$ & Não documentado. \\
\hline Microcistinas & Hepatotóxico & $\begin{array}{l}\text { Mais de } \\
\text { cinqüenta }\end{array}$ & $\begin{array}{l}\text { Em hepatócitos, inibição da fosfatase } \\
\text { protéica e ativação da fosfolipase A2 } \\
\text { e da ciclooxigenase. Inibição da } \\
\text { fosfatase protéica } 1 \text { e } 2 \mathrm{~A} \text {, causando } \\
\text { hiperfosforilação das proteínas } \\
\text { associadas com o citoesqueleto, } \\
\text { levando à deformidade celular. Em } \\
\text { macrófagos, indução da produção de } \\
\text { FNT e IL-1, culminando com a } \\
\text { ativação da ciclooxigenase. }\end{array}$ & $\begin{array}{l}\text { Taquicardia, colapso, } \\
\text { exagerada respiração } \\
\text { abdominal, cianose, } \\
\text { convulsões e morte. }\end{array}$ \\
\hline Nodularina & Hepatotóxico & Cinco & $\begin{array}{l}\text { Indução de mudanças nos } \\
\text { microfilamentos de actina e outros } \\
\text { elementos do citoesqueleto, } \\
\text { consequiente destruição das células da } \\
\text { camada sinusóide endotelial. }\end{array}$ & $\begin{array}{l}\text { Taquicardia, dano } \\
\text { hepático, carcinogênese, } \\
\text { colapso, exagerada } \\
\text { respiração abdominal, } \\
\text { cianose, convulsões e } \\
\text { morte. }\end{array}$ \\
\hline Cilindrospermopsina & Hepatotóxico & - & $\begin{array}{l}\text { Ação citotóxica. Deslocamento dos } \\
\text { ribossomos para o centro da célula, } \\
\text { diminuição do P-450 dos } \\
\text { microssomos hepáticos, acumulação } \\
\text { de gotículas de gordura na porção } \\
\text { central dos lóbulos hepáticos. }\end{array}$ & $\begin{array}{l}\text { Anorexia, leve diarréia, } \\
\text { respiração ofegante e } \\
\text { possível morte entre } 6 \text { e } 9 \\
\text { horas. }\end{array}$ \\
\hline $\begin{array}{l}\text { Lipopolissacarídeos - } \\
\text { Endotoxina }\end{array}$ & $\begin{array}{l}\text { Choque } \\
\text { tóxico }\end{array}$ & Mais de três & $\begin{array}{l}\text { Distúrbios gastrintestinais, choque } \\
\text { tóxico e inflamação. }\end{array}$ & $\begin{array}{l}\text { Gastroenterite, irritação } \\
\text { cutânea, irritação ocular, } \\
\text { reações alérgicas e asma. }\end{array}$ \\
\hline
\end{tabular}




\section{Casos clínicos}

Em 1979, numa comunidade aborígene fora da costa de Queensland, na Austrália, foram notificados 150 casos de hepatoenterite. Desses, havia 140 crianças e dez adultos. Exame clínico detalhado mostrou mal-estar, anorexia, vômitos, dor de cabeça, hepatomegalia, constipação com posterior diarréia e vários níveis de desidratação. A análise da urina mostrou perda de eletrólitos, presença de glicose, corpos cetônicos, sangue e proteínas na urina, sugerindo extenso dano renal. A análise do sangue mostrou elevados níveis de enzimas hepáticas em algumas crianças, indicando dano hepático. Houve choque hipovolêmico nos casos mais severos. Após receberem apropriado tratamento, os pacientes recuperaram-se. Toda a população afetada recebia água da represa Solomon, sobre a qual havia reclamações de mal-cheiro e gosto desagradável. Posteriormente, um monitoramento da represa identificou a cianobactéria Cylindrospermopsis raciborskii como a causadora das freqüentes florações. Em certas épocas, a concentração celular foi superior a 300.000 células por ml. Essa espécie não forma scum, e não se concentra na superfície do corpo d'água. A desestratificação de todo o reservatório foi a forma escolhida pelas autoridades locais a fim de eliminar a floração tóxica ${ }^{49}$.

Em 1988, a represa de Paulo Afonso na Bahia causou em 42 dias, 2.000 casos de gastroenterite severa, com 88 destes resultando em morte. As amostras de sangue e fezes dos pacientes foram submetidas à análise bacteriológica, virológica e toxicológica. A água utilizada para consumo foi analisada com relação à presença de microorganismos e metais pesados. Após a revisão dos dados clínicos e dos testes com amostras da água, os resultados demonstraram que a água concentrada na represa possuía cianobactérias, e as suas toxinas foram responsáveis pelo incidente, que se restringiu à área abastecida pela represa. As cianobactérias dos gêneros Anabaena e Microcystis foram identificadas na água não-tratada, na quantidade de 1.104 a 9.755 unidades formadoras de colônia (UFC) por mililitro. Nenhuma outra toxina ou agente infeccioso foi identificado ${ }^{50}$.

Em fevereiro de 1996, na cidade de Caruaru, no estado de Pernambuco, 116 de 131 pacientes de uma clínica de hemodiálise sofreram distúrbios visuais, náusea, vômitos, fraqueza muscular e hepatomegalia durante a rotina de tratamento. Posteriormente, 100 desses pacientes sofreram dano hepático agudo e, em dezembro de 1996, 52 deles morreram. A morte foi atribuída à denominada "Síndrome de Caruaru" ${ }^{51}$.

${ }^{49}$ CHORUS \& BARTRAM, 1999.

50 TEIXERA et al., 1993.

${ }^{51}$ CARMICHAEL et al, 2001. 
Os dados laboratoriais mostraram transaminases elevadas, hiperbilirrubinemia variável, tempo de protrombina prolongado e altas taxas de triglicerídeos. O exame histopatológico em microscópio óptico mostrou deformidade dos hepatócitos, necrose, apoptose, vacuolização do citoplasma e hepatócitos multinucleados. Na microscopia eletrônica, foram observados edema intracelular, danos nas mitocôndrias e nos retículos endoplasmáticos lisos e rugosos. Os tipos de lesões identificadas nos exames microscópicos foram idênticos aos encontrados em experiências em animais, envolvendo exposição à microcistina ${ }^{52}$. Acerca dessas características, 0 incidente foi atribuído a cianotoxinas. Em análises anteriores realizadas nos reservatórios de abastecimento, foi demonstrada a presença dominante de cianobactérias durante os meses de verão desde 1990. A comparação das análises do filtro de carbono e resina do sistema de tratamento de água da clínica com as análises do tecido hepático dos pacientes contaminados levou à identificação de duas cianotoxinas: a microcistina, presente em todos os testes, e a cilindrospermpsina, presente nos testes de carbono e resina ${ }^{53}$. O que contribuiu para a morte dos pacientes foi a exposição à microcistina por via intravenosa, especificamente as microcistinas -YR, -LR e -AR. A presença das microcistinas foi atribuída à falha no tratamento da água usada na hemodiálise ${ }^{54}$.

\section{Controle de algas e legislação}

Conforme mencionado, utilizam-se produtos químicos para controle de algas em corpos hídricos e, principalmente, para a água destinada ao consumo humano. O uso de tais produtos, chamados algicidas, como o sulfato de cobre e o peróxido de hidrogênio, muitas vezes, é feito sem controle e sem prévia avaliação ambiental. Isso não é adequado, visto que pode causar efeitos adversos, como toxicidade a organismos não-alvo. A eliminação das florações de algas faz com que liberem, após a lise celular, suas toxinas para o meio externo $0^{55}$. Essa prática não se mostra adequada para a eliminação de toxinas, elevando os custos do tratamento de água e aumentando o número de substâncias químicas na água ${ }^{56}$.

De acordo com a legislação brasileira, os algicidas, são classificados como agrotóxicos e afins em função de sua ação biocida. Desse modo, apresentam o mesmo significado toxicológico dos demais agrotóxicos. Todavia, apesar de seu

${ }^{52}$ CHORUS, 1999; AZEVEDO et al., 2002.

${ }^{53}$ CARMICHAEL et al., 2001; AZEVEDO et al., 2002.

${ }^{54}$ CHORUS \& BARTRAM, 1999.

${ }^{55}$ MAXIMIANO et al, 2004.

${ }^{56}$ CHORUS \& BARTRAM, 1999. 
uso disseminado, os únicos algicidas registrados no Brasil têm autorização apenas para uso na manutenção de piscinas ${ }^{57}$.

A lei $n^{\circ} 7.802$, de 11 de julho de 1989 define os agrotóxicos e afins e é regulamentada por outras publicações. Além disso, no que diz respeito ao controle das atividades utilizadoras de recursos ambientais consideradas efetivamente ou potencialmente poluidoras e capazes de causar degradação ambiental, a Resolução do Conselho Nacional de Meio Ambiente (CONAMA) nº 237, de 19.12.97, estabelece a necessidade de prévio licenciamento ambiental do órgão competente sem prejuízo de outras licenças legalmente exigíveis. No âmbito desta resolução, destacam-se as atividades de manejo de recursos aquáticos vivos.

Sobre os parâmetros de qualidade de água, a Resolução CONAMA nº 20, de 18.06.86, estabelece os critérios para a classificação das águas doces, salobras e salinas e a Portaria da Fundação Nacional de Saúde (FUNASA) n 1.469, de 29.12.00, estabelece os parâmetros relativos à qualidade da água para consumo humano e seu padrão de potabilidade ${ }^{58}$. No entanto, não há nenhuma disposição normativa brasileira a respeito da concentração de cianotoxinas em corpos d'água, reservatórios, represas, etc. Isso se deve à falta de dados relativos à exposição de humanos e animais à cianotoxinas e outros componentes. A Organização Mundial de Saúde pôde estabelecer valor de diretriz à microcistina-LR por via oral, que é de $1,0 \mathrm{mg} / \mathrm{L}$, considerando-se um adulto de $60 \mathrm{~kg}$ que faz consumo diário de 2 litros de água por dia e que sua exposição diária tolerável seja de $0,04 \mathrm{mg} / \mathrm{Kg}$ de peso corpóreo. O cálculo feito para obter esse valor levou em consideração a exposição diária tolerável (TDI), o aproximado consumo diário (em litros), o peso corpóreo. A proporção feita pela razão da exposição diária tolerável e pelo consumo de água também foi considerada. Esse valor considera apenas a exposição pela água, por meio do consumo, portanto a exposição por alimentos contaminados ou pelo ar não pôde ser avaliada ${ }^{59}$.

Ressalta-se que a Portaria SVS no 03/92 estabelece a monografia técnica dos produtos agrotóxicos, documento que dá publicidade ao deferimento de ingrediente ativo junto à vigilância sanitária e define autorização de uso para os vários tipos de ambiente, além do estabelecimento de doses e culturas. Segundo a ANVISA (2003), no Brasil, não há produtos registrados para o controle de algas em reservatórios.

${ }^{57}$ MAXIMIANO et al, 2005.

${ }^{58}$ MAXIMIANO et al, 2005.

${ }^{59}$ CHORUS \& BARTRAM, 1999. 


\section{Considerações finais}

Tendo em vista a gravidade do risco das cianobactérias e suas toxinas para a saúde pública, faz-se necessária, pelos órgãos competentes, a elaboração de planos de gerenciamento dos ambientes hídricos para manter sob controle as florações tóxicas de cianobactérias. Além disso, é importante a fiscalização das atividades ilegais de controle das algas que prejudicam o meio ambiente por meio do despejo de resíduos orgânicos. Porém, antes disso, é necessário que normas sejam elaboradas para que o órgão competente possa regular a questão. Segundo Maximiano et al (2005), a melhoria das políticas de saneamento público e a adequação de práticas em centrais de distribuição de água podem reduzir o problema consideravelmente, visto que o desconhecimento, neste caso, tem grande importância. As medidas preventivas possuem mais eficácia que os planos ou políticas de emergência, tanto do ponto de vista dos aspectos sociais e econômicos, quanto em relação à saúde pública.

A contaminação de organismos aquáticos por cianotoxinas precisa ser estudada para que seja possível realizar melhor contextualização do problema. As pesquisas devem levar em consideração a interação entre organismo aquático, meio ambiente e cianotoxinas, já que estudos de laboratório são satisfatórios com relação à análise quantitativa, contudo não consideram tal interação. É importante ressaltar que políticas de conscientização, educação ambiental e social sejam realizadas, pois, desta forma, a eutrofização artificial pode reduzir-se drasticamente. A contaminação dos ambientes hídricos por cianotoxinas, na maioria dos casos, é resultado da ação ser humano e traz prejuízo a outras espécies presentes no ambiente.

\section{Referências}

ANVISA (Agência Nacional de Vigilância Sanitária). Toxicologia-Monografias de agrotóxicos. http://www.anvisa.gov.br/toxicologia/monografias/index.htm. [On-line]. Consultado em março de 2005.

AZEVEDO, S. M. F. O. et alli. "Human intoxication by microcystins during renal dialysis treatment in Caruaru - Brazil”. In: Toxicology, 181-182: 441-446, 2002.

BEATTIE, K. A. et alli. "Three dehydrobutyrine (Dhb)-containing microcystins from the cyanobacterium". In: Nostoc sp. Phytochemistry, 47(7): 1289-1292, 1998.

BRYANT, D. A. The molecular biology of cyanobacteria. Dordrecht: Kluwer Academic Publishers, 1994.

CAMPOS, V.et alli. "Microcystin in cyanobacterial blooms in chilean Lake". In: Systematic 
and Applied Microbiology., 22(2): 73-169, 1999.

CARMICHAEL, W. W. et alli. "Human fatalities from cyanobacteria: chemical and biological evidence for cyanotoxins”. In: Environmental Health Perspectives, 109(7): 663-668, 2001.

CHISWELL, R. K. et alli. "Stability of cylindrospermopsin, the toxin from Cyanobacterium Cylindrospermopsis raciborskii. Effects of $\mathrm{pH}$, temperature and sunlight on decomposition. In: Environmental Toxicology, 14(1): 155-161, 1999.

CHORUS, I. \& BARTRAM, J. Toxic cyanobacteria in water: A guide for their public health consequences, monitoring and management. London: E\&FN Spon, 1999.

CODD, G. A. \& BELL, S. G. The occurrence and fate of blue-green algae in fresh-waters. National Rivers Authority Research and Development Report 29, London: Her Majesty's Stationary Office, 1996.

DEMOTT, W. R.; ZHANG, Q.; CARMICHAEL, W. W. "Effects of toxic cyanobacteria and purified toxins on the survival and feeding of a copepod and three species of Daphnia". In: Limnology and Oceanography, 36 (7): 1346-1357, 1991.

DITTMAN, E.et alli. "Insertional mutagenesis of a peptide synthetase gene which is responsible for hepatotoxin production in the cyanobacterium Microcystis aeruginosa PPC 7806”. In: Molecular Microbiololgy, 26: 779-787, 1997.

DUY, T. N. et alli. "Toxicology and risk assessment of freshwater cyanobacterial (blue green algal) toxins in water". In: Review of Environmental Contamination and Toxicology, 163: 113-186, 2000.

ESTEVES, F. A. Fundamentos de Limnologia, Rio de Janeiro: Interciência, 1998.

FERNANDES, L. F.; LAGOS, P. E.; VENTURA, C. "Florações de cianobactérias e eutrofização no reservatório do Irai”. Curitiba, PR. II: Distribuição horizontal de algumas espécies. In: IV Seminário do Projeto Interdisciplinar sobre Eutrofização de Águas de Abastecimento Público na Bacia do Altíssimo Iguaçu, Curitiba, 2003.

MAXIMIANO, A. A. et alli. "Utilização de drogas veterinárias, agrotóxicos e afins em ambientes hídricos: demandas, regulamentação e considerações sobre riscos à saúde humana e ambiental". In: Ciência e Saúde Coletiva, 18(2): no prelo, 2005.

MEISSNER, K.; DITTMAN, E.; BORNER, T. "Toxic and non-toxic strains of the cyanobacterium Microcystis aeruginosa contain sequence homologous to peptide synthetase genes”. In: FEMS Microbiology Letters, 135: 295-303, 1996.

OLIVEIRA, E. C. Introdução à biologia vegetal, São Paulo: EDUSP, 1996.

OLIVEIRA-FILHO, E. C. \& LIMA, J. E. F. Potencial de impacto da agricultura sobre os recursos hídricos na região do cerrado. (Documentos 56/ Embrapa Cerrados) Planaltina-DF: Embrapa Cerrados, 2002.50p.

PINHO, G. L. L. et alli. "Toxic effects of microcystins in the hepatopancreas of the estuarine crab". In: Chasmagnathus granulatus (Decapoda, Grapsidae). Comparative biochemistry and physiology, 135 (C): 459-468, 2003.

RESSOM, R. et alli. Health effects of toxic cyanobacteria (blue-green algae). Canberra, 
Australia: Australia Government Public Service, 1994.

TEIXERA, M. et alli. "Gastroenteritis epidemic in the area of the Itaparica Dam, Bahia, Brazil”. In: Bulletin of the Pan American Health Organization, 27(3): 244-253, 1993.

TRABULSI, L. R.et alli. Microbiologia. São Paulo: Atheneu, 1999.

VON SPERLING, M. Introdução à qualidade das águas e tratamento dos esgotos. Belo Horizonte: Departamento de Engenharia Sanitária e Ambiental - UFMG, 1996.

WAKIDA, F. T. \& LERNER, D. N. "Non-agricultural sources of groundwater nitrate: a review and case study”. In: Water Research, v. 39: p. 3-16, 2005.

WATANABE, M. F., OISHI, S. "Effects of environmental factors on toxicology of a cyanobacterium (Microcystis aeruginosa) under culture conditions”. In: Applied and Environmental Microbiology, 49(5): 1342-1344, 1985.

YUNES, J. S.et alli. "Effect of nutrient balance and physical factors on blooms of toxic cyanobacteria in the Patos Lagoon, southern Brazil". In: Verh. International Verein.Limnology, 26: 1796-1800, 1998. 
Para publicar na revista Universitas - Ciências da Saúde, encaminhe seu artigo original para:

Campus do Centro Universitário de Brasília UniCEUB, SEPN 707/907, Bloco 9, Faculdade de Ciências da Saúde, CEP 70.790-075, Brasília-DF.

e-mail: universitas.saude@uniceub.br

Aos cuidados do Editor da revista.

Observe as Normas de Publicação. 